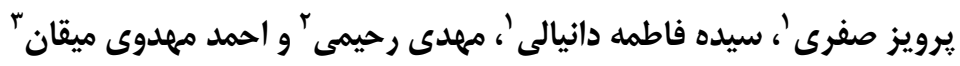 \\ 1- دانش أموخته دكترى، كروه به نزادى و بيوتكنولوزى كياهى، دانشكده كشاورزى ، دانشكاه تبريز، تبريز، ايران

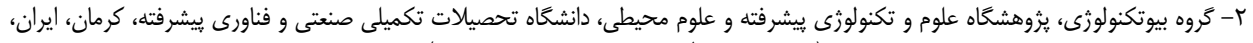

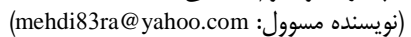 \\ ب- دانشجوى دكترى اصلاح نباتات، كروه زراعت و اصلاح نباتات، دانشكده علوم كشاورزى، دانشخاه كيلان، رشت، ايران

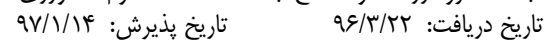 \\ صفحه: 191 تاريخ
}

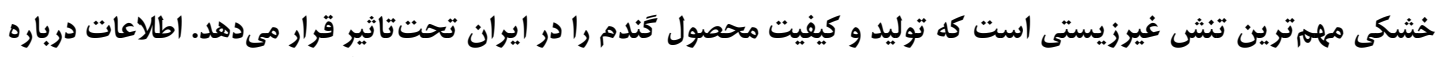

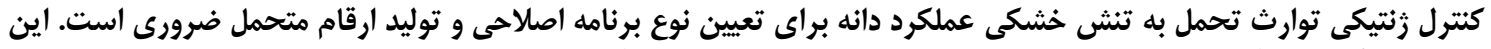

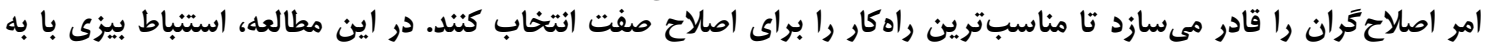

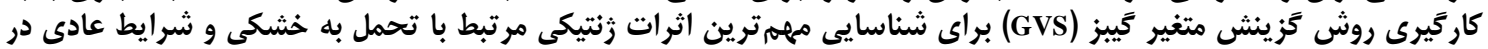

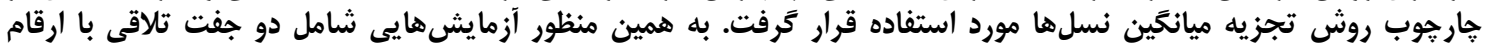

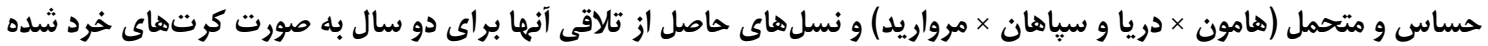

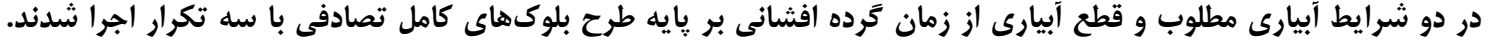

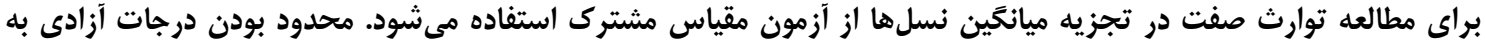

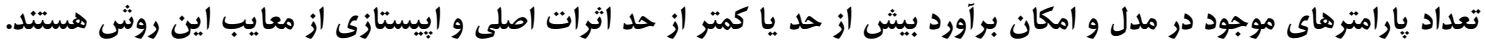

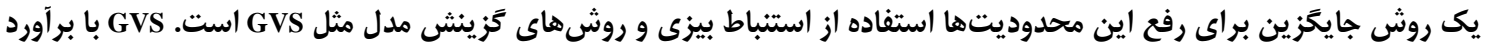

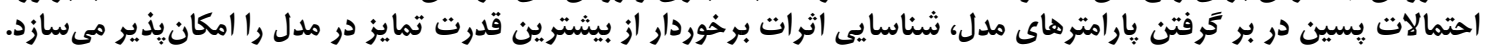

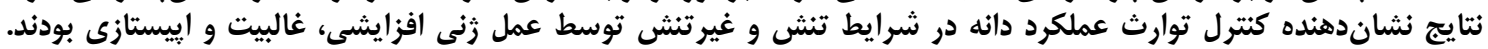

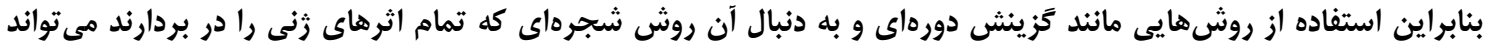

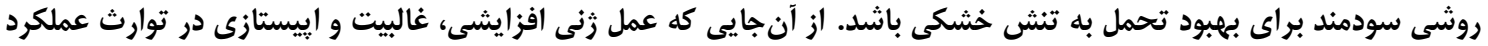

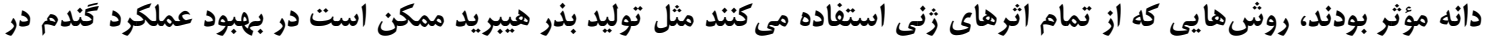
شرايط مختلف مؤثر باشد.

وازههاى كليدى: آزمون مقياس مشتر كي، استنباط بيزى، تجزيه ميانكَين نسلها

در هر دو شرايط محيطى توسط اثرات فوق غلبهى زنها

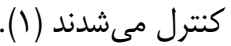

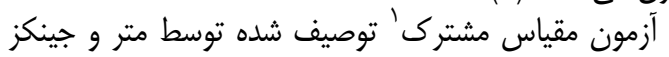

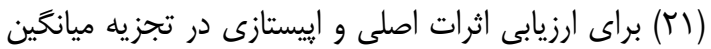

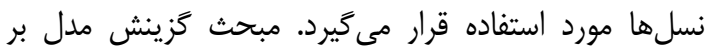

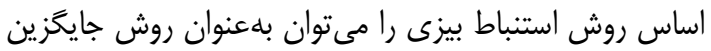

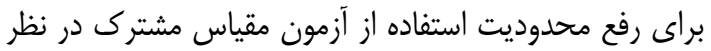

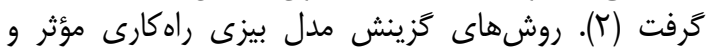

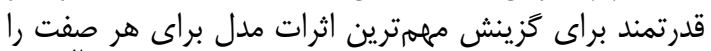

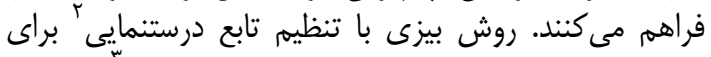

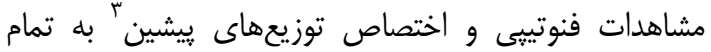

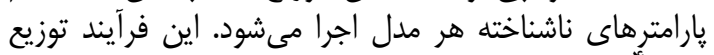

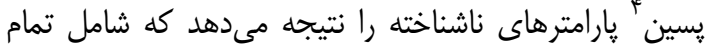

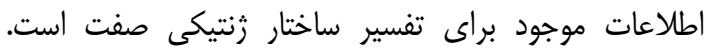

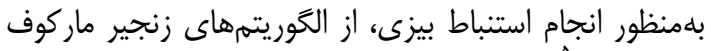

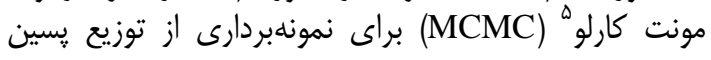

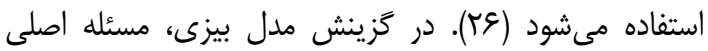

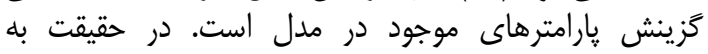

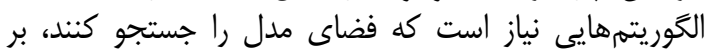

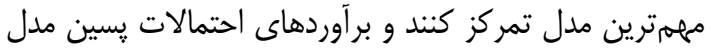

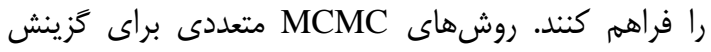

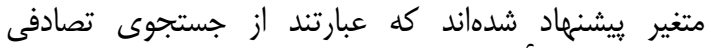

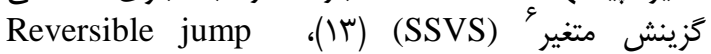

مقدمه

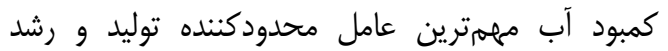

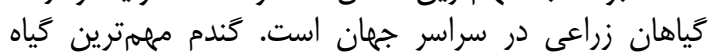

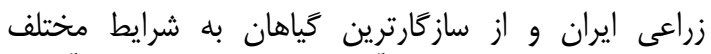

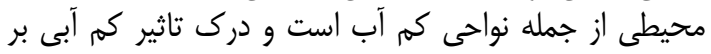

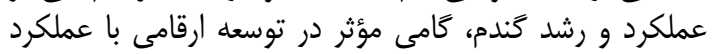

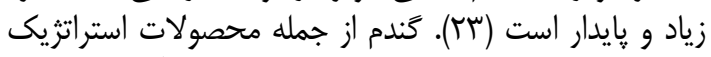

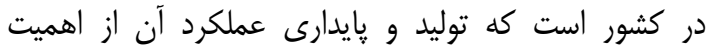

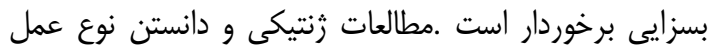

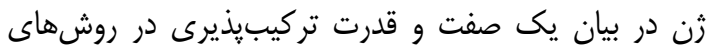

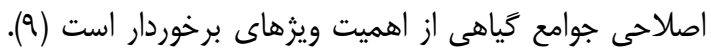

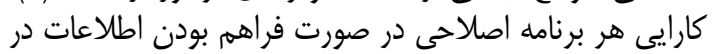

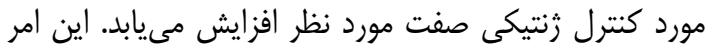

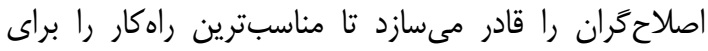

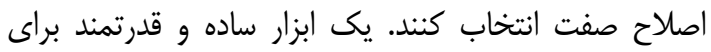

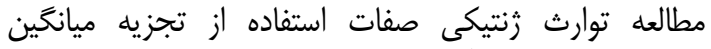

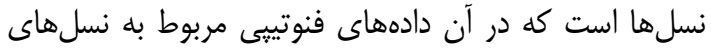

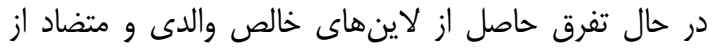

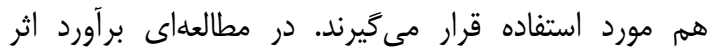

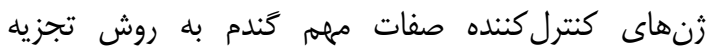

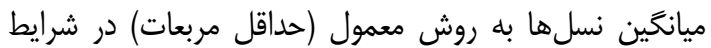

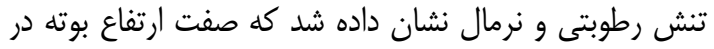
شرايط بدون تنش و صفات طول سنبله اصلى و وزن هزان ارتفار دانه

1- Joint scaling test

4- Posterior distribution

2- Likelihood function

5- Markov Chain Monte Carlo

3- Prior distribution

6- Stochastic Search Variable 
نسل ها در كرتهاى فرعى با شش و نه سطح (به ترتيب براى

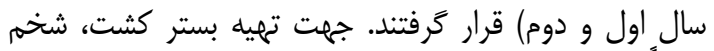

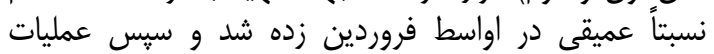

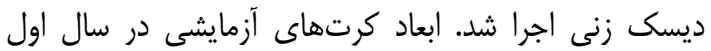
(

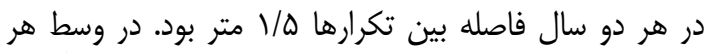

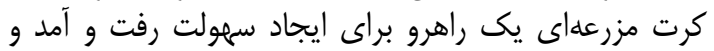

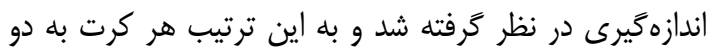

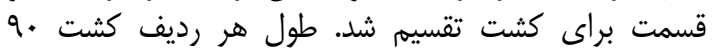

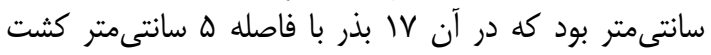

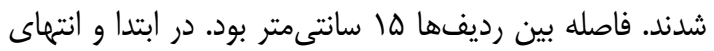

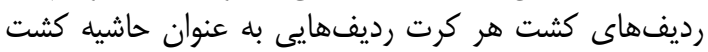

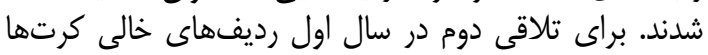

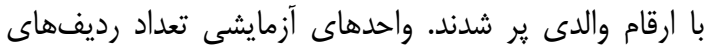

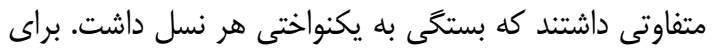

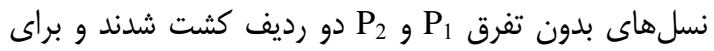

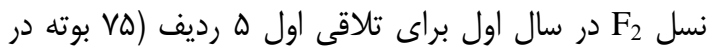

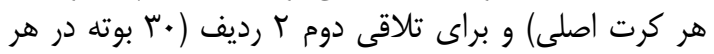

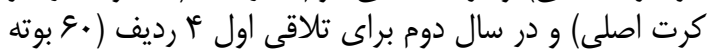

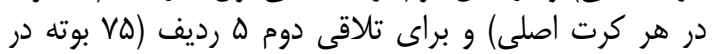

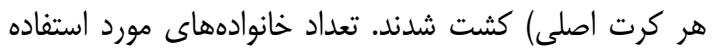

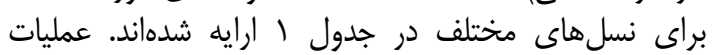

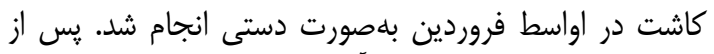

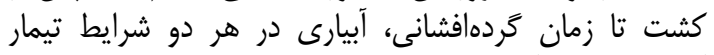

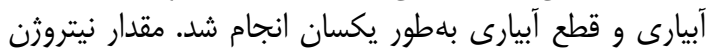

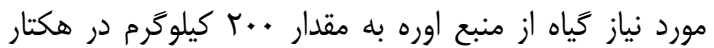

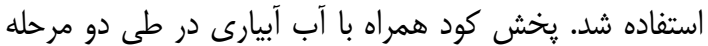

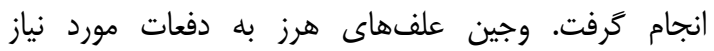

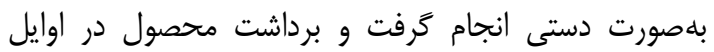
شهريور بلهصورت دستى انجام شد. مواد كياهى مورئ مورد استفاده

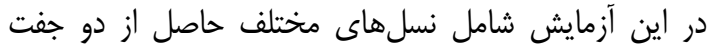

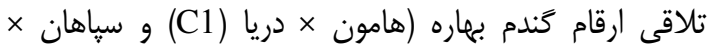

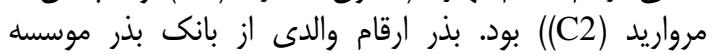

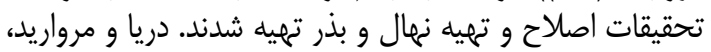

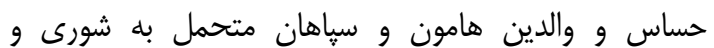

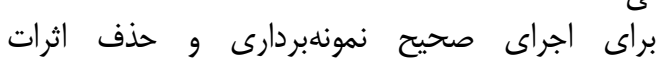

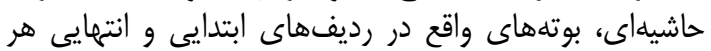

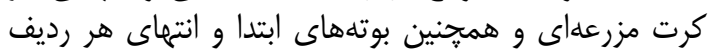

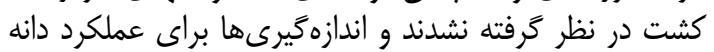

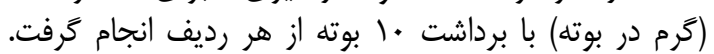

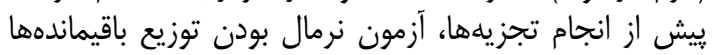

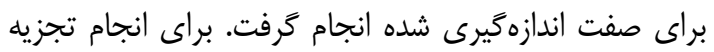

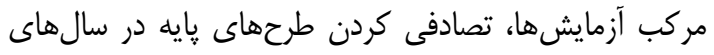

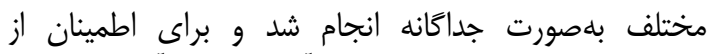

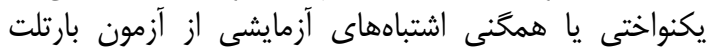

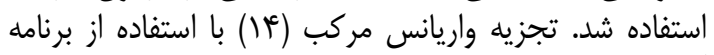

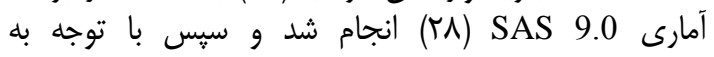
معنىدارى اثر متقابل نسل × سال بلهطور جداخانه براى هر تران
Metropolis

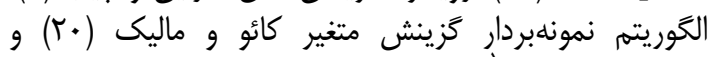

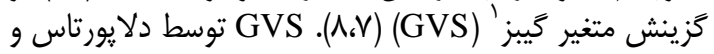

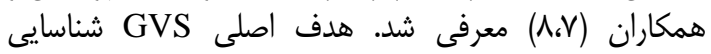

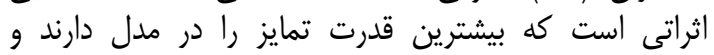

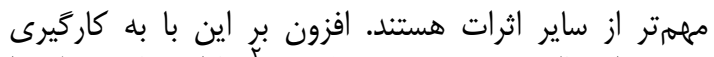

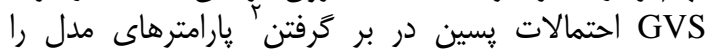

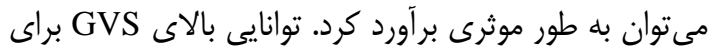

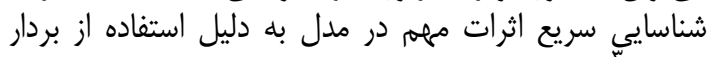
دودويى" و الخوريتم MCMC مؤثر (الكَوريتم نمونهبردار Gibbs

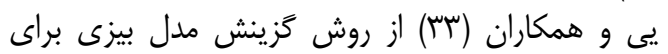

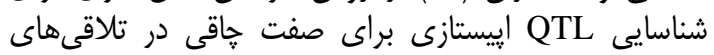

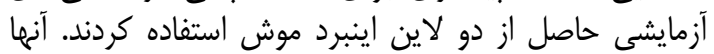
يك الكوريتم MCMC موثر را با استفاده از الكوريتمهاى إني نمونهبردار Gibbs و Metropolis- Hasting براى به دون دست

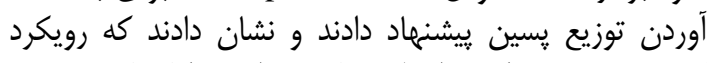

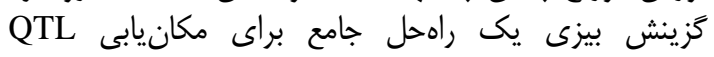

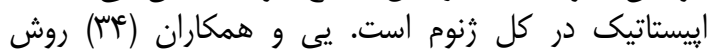

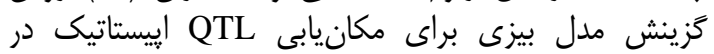

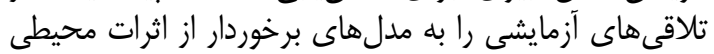

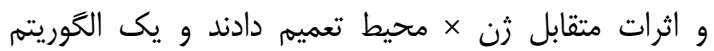

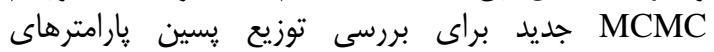

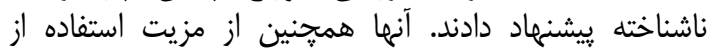

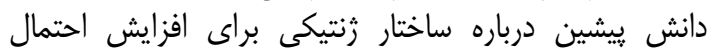

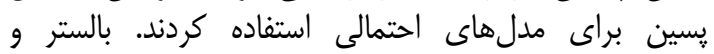

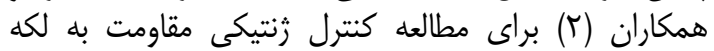

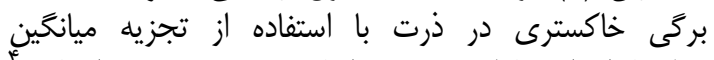

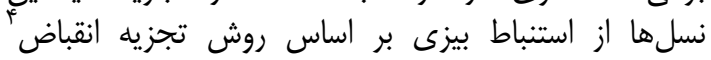

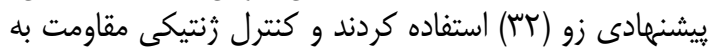

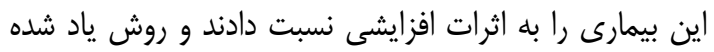

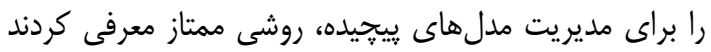

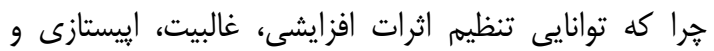
واريانس آنها را در يك مدل ساده دانئ دارا است.

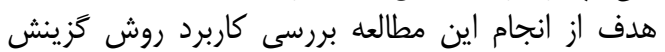

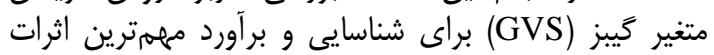

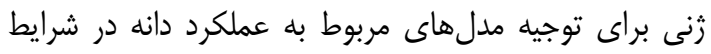
تنش و غير تنش بود.

نسلهاى دوم) و

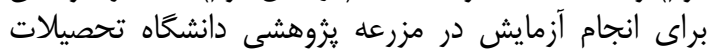

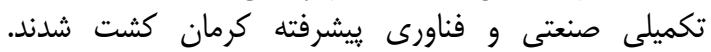

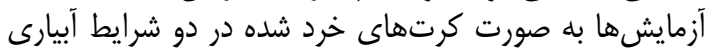

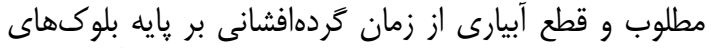

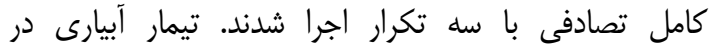
كرتهاى اصلى شامل دو سطح (آبيارى و قطع آبيارى) و و 1- Gibbs Variable Selection $\quad$ 2- Posterior inclusion probabilities $\quad$ 3- Binary 4- Shrinkage analysis 
معنىدارى اثر متقابل نسل × تيمار، تجزيههاى بعدى بلهطور جداًانه در هر سطح تنش انجام شد.
سال تجزيه واريانس براى شناسايى تفاوتهاى معنىدار ميان

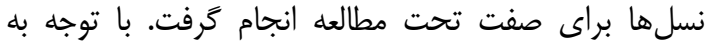

Table 1. The number of families for different generations

\begin{tabular}{|c|c|c|c|c|}
\hline \multicolumn{2}{|c|}{ سياهان × مرواريد (C2) } & \multicolumn{2}{|c|}{ هامون × دريا (C1) } & \multirow{2}{*}{ ا نسلها } \\
\hline 1490 & 1494 & 1490 & $14 q 4$ & \\
\hline$r+$ & IV & $r$. & r. & $\mathrm{F}_{3}$ \\
\hline 10 & - & $r$. & - & $\mathrm{F}_{4}$ \\
\hline 10 & 19 & Ir & $r$. & $\mathrm{BC}_{1} \mathrm{~S}_{1}$ \\
\hline $1 f$ & 10 & ir & $r$. & $\mathrm{BC}_{2} \mathrm{~S}_{1}$ \\
\hline la & - & 19 & - & $\mathrm{BC}_{1} \mathrm{~S}_{2}$ \\
\hline 10 & - & 19 & - & $\mathrm{BC}_{2} \mathrm{~S}_{2}$ \\
\hline
\end{tabular}

جدول 1- تعداد خانوادهها براى نسل هاى مختلف

بهدست نمى آورد و تاثيرى بر توزيع بِسين واقعى بارامترهاى

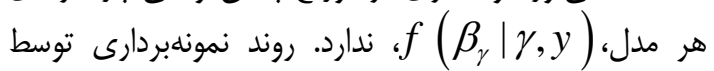
مراحل زير خلاصه مىشود (هار):

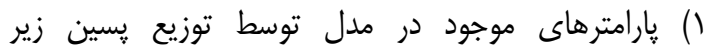

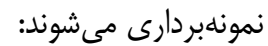

$f\left(\beta_{\gamma} \mid \beta_{\gamma}, \gamma, y\right) \propto f(y \mid \beta, \gamma) f\left(\beta_{\gamma} \mid \gamma\right)$ $f\left(\beta_{\gamma} \mid \beta_{\gamma}, \gamma\right)$

r) پارامترهاى خارج شده از مدل از توزيع يِيشين كاذب

$f\left(\beta_{\gamma} \mid \beta_{\gamma}, \gamma, y\right) \propto f\left(\beta_{\gamma} \mid \beta_{\gamma}, \gamma\right)$

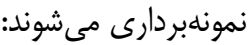

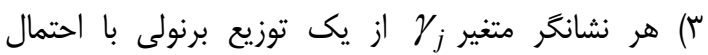
موفقيت رابطه زير محاسبه مى شود: $O_{j}=\frac{f\left(y \mid \beta, \gamma_{j}=1, \gamma_{\backslash_{j}}\right)}{f\left(y \mid \beta, \gamma_{j}=0, \gamma_{\backslash_{j}}\right)} \frac{f\left(\beta \mid \gamma_{j}=1, \gamma_{\backslash_{j}}\right)}{f\left(\beta \mid \gamma_{j}=0, \gamma_{\backslash_{j}}\right)}$ $\frac{f\left(\gamma_{j}=1, \gamma_{\backslash_{j}}\right)}{f\left(\gamma_{j}=0, \gamma_{\backslash_{j}}\right)}$

انتخاب توزيعهاى ييشين و وييشين كاذب جنبه بسيار

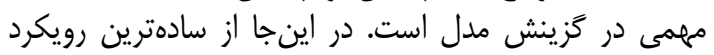
كه در آن (ر) و ييشين كاذب است، استفاده شد: $f(\beta \mid \gamma)=\prod_{j=1}^{p} f\left(\beta_{j} \mid \gamma_{j}\right)$

در جنين مواردى، يك انتخاب معمول و ساده از توسط رابطه زير حاصل مى شود: $f\left(\beta_{j} \mid \gamma_{j}\right)$ $f\left(\beta_{j} \mid \gamma_{j}\right)=\left(1-\gamma_{j}\right) f\left(\beta_{j} \mid \gamma_{j}=0\right)$ $+\gamma_{j} f\left(\beta_{j} \mid \gamma_{j}=1\right)$

كه توزيع ييشين واقعى ييشين كاذب مى دهد.

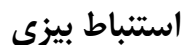

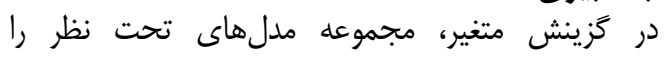

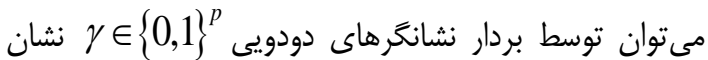

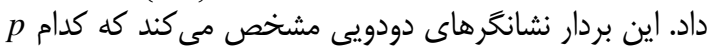

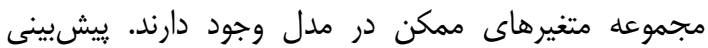
كننده خطى را مىتوان بلصورت زير نوشت مهاي (ه):

$$
\eta=\sum_{j=1}^{p} \gamma_{j} x_{j} \beta_{j}
$$

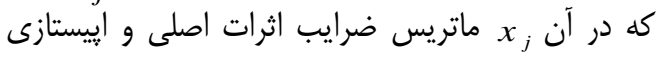
دو ثنى و عبارت زام است.

در GVS درستنمايى هر مدل توسط $f(\beta, \gamma)=f(\beta \mid \gamma) f(\gamma)$ توزيع اختصاص داده مى شود كه در آن (رار

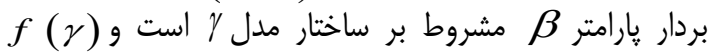

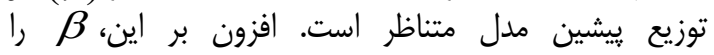
مى توان به دو بردار رئ

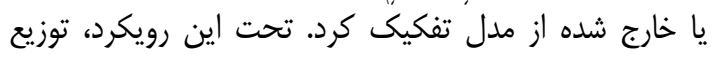

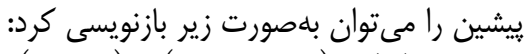
$f(\beta, \gamma)=f\left(\beta_{\gamma} \mid \gamma\right) f\left(\beta_{\gamma} \mid \beta_{\gamma}, \gamma\right) f(\gamma)$ از آنجا كه از ييشيينى كننده خطى رابطه (ا) استفاده

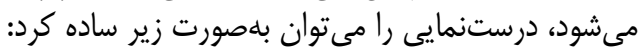
$f(y \mid \beta, \gamma)=f\left(y \mid \beta_{\gamma}, \gamma\right)$

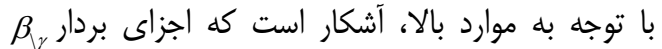

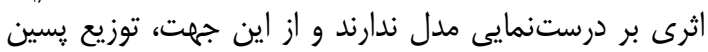

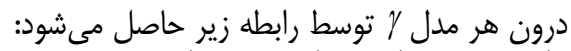

(₹) $f(\beta \mid \gamma, y)=f\left(\beta_{\gamma} \mid \gamma, y\right) \times f\left(\beta_{\gamma} \mid \beta_{\gamma}, \gamma\right)$ كه در آن

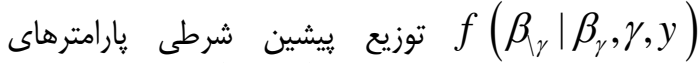
كنجانده نشده در مدل $\gamma$ است. عنوان توزيع بيشين واقعى مدل تفسير كرد در حالى كه توزيع f $f\left(\beta_{\gamma} \mid \beta_{\gamma}, \gamma\right)$

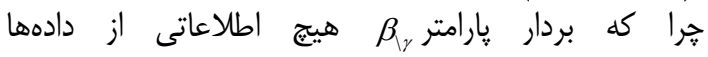


صورتى كه خود همبستخى ها كم باشند، همخرايى در تعداد

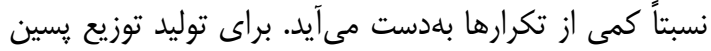

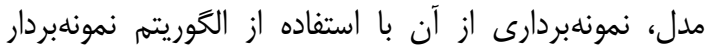
Gibbs فرمز WinBUGS نرمافزارى رايكان است كه نمونهبردارى Gibbs را انجام مىدهد (www.mrc-bsu.com.ac.uk/bugs).

نتايج و بحث

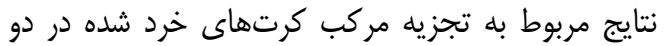

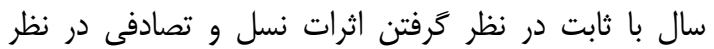

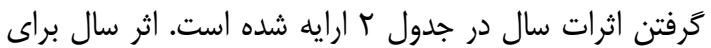

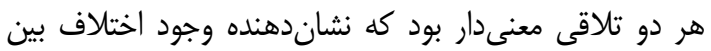

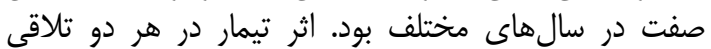

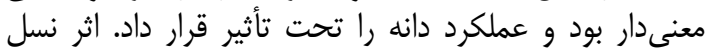

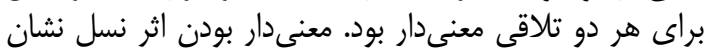

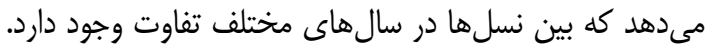

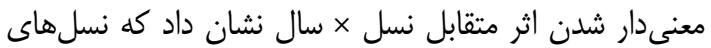

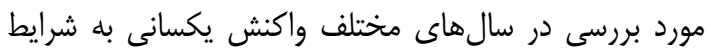

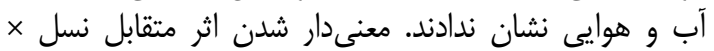

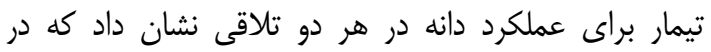

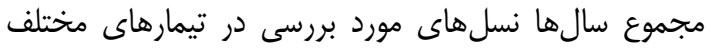

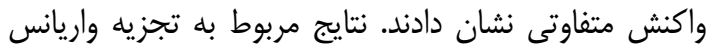

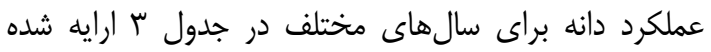

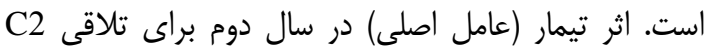

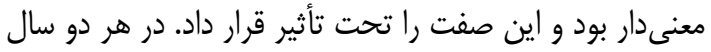

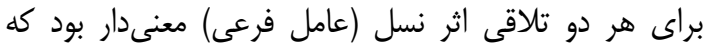

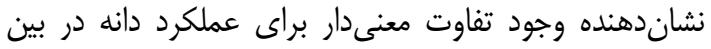

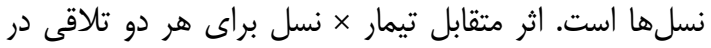

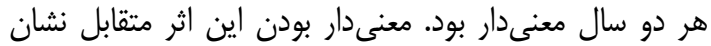

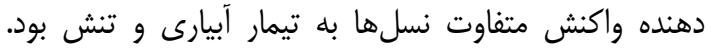

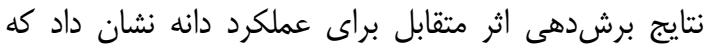

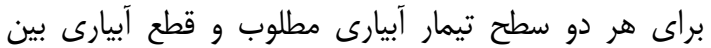

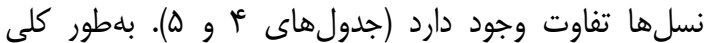

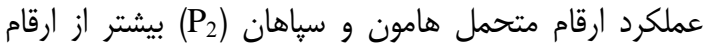

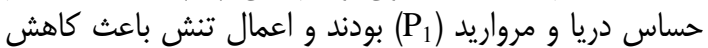

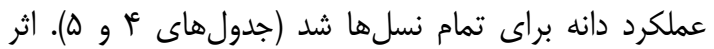

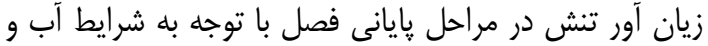

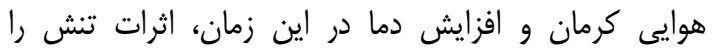

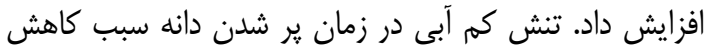

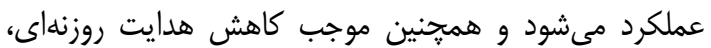

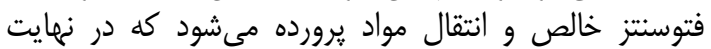

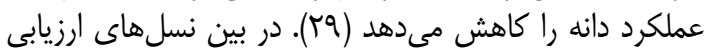

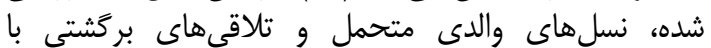
والدهاى متحمل در اكثر موارد برتر بودند.

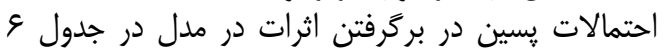

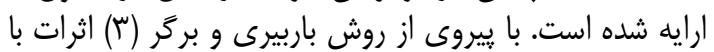

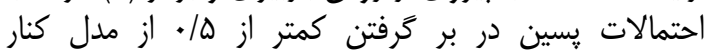

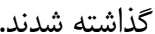

توزيع ييشين فوق را مىتوان بلهور كارآمدى در هر

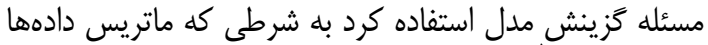

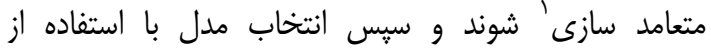
دادههاى جديد تبديل شده انجام كيرد (ج) (ج).

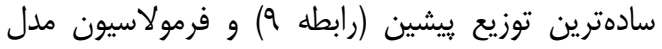

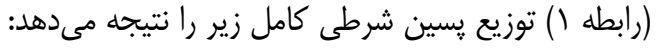

$f\left(\beta_{j} \mid \gamma_{j}, \beta_{j}, y\right) \propto f\left(y \mid \beta_{\gamma}, \gamma\right) \prod_{k=1}^{n} f\left(\beta_{k} \mid \gamma_{k}\right)$

$\left\{\begin{array}{l}f(y \mid \gamma, \beta) f\left(\beta_{j} \mid \gamma_{j}=1\right) \\ f\left(\beta_{j} \mid \gamma_{j}=0\right)\end{array}\right.$

كه نشاندهنده اين است كه توزيع ييشين كاذب، مل f $f\left(\beta_{j} \mid \gamma_{j}=0\right)$ مدل ندارد.

مشابه با كيورى و مك مكلاك (سار) از تركيبى از توزيع نرمال براى يارامترهاى مدل استفاده شد:

$f\left(\beta_{j} \mid \gamma_{j}=1\right) \equiv N\left(0, \sum_{j}\right)$

$f\left(\beta_{j} \mid \gamma_{j}=0\right) \equiv N\left(\overline{\mu_{j}}, \overline{S_{j}}\right)$

و إرار

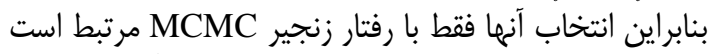

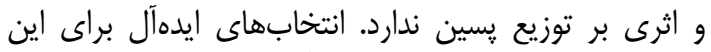

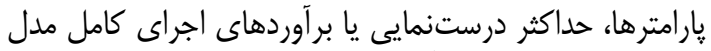

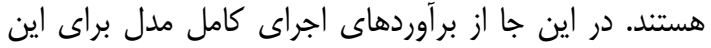

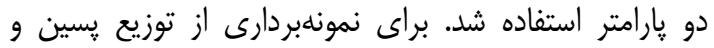

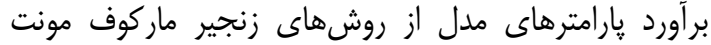

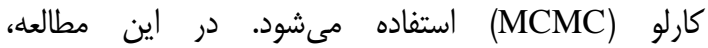
نمونهبردارى توسط الكوريته نمونهبردار كرفت. نمونهبردارى Gibbs شامل فرآيند تكرارى كسب كراري

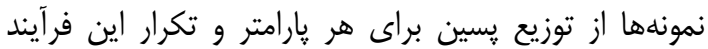

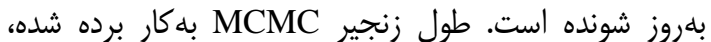

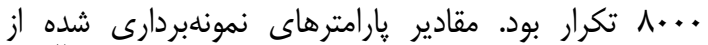

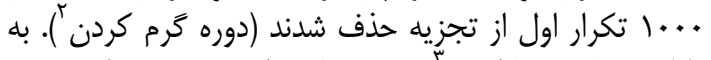

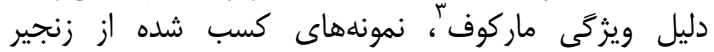

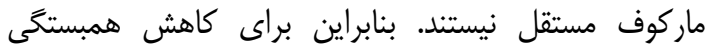

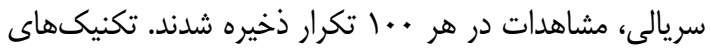

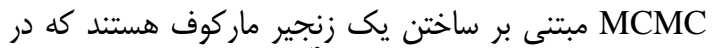

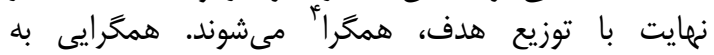

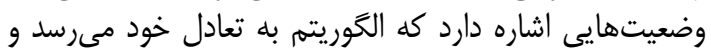

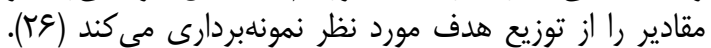

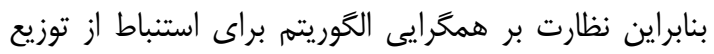

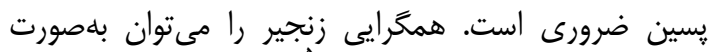

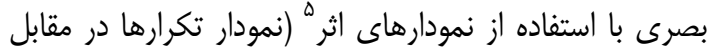

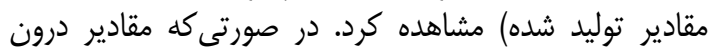

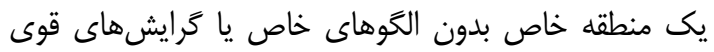

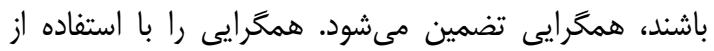

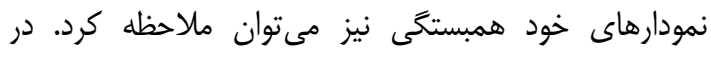

\begin{tabular}{llll}
\hline 1- Orthogonalize & 2- Burn-in period & 3- Markov property & 4- Convergence
\end{tabular}




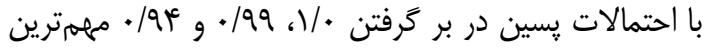

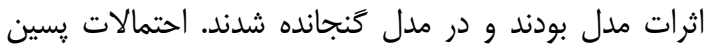

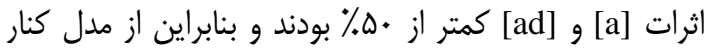

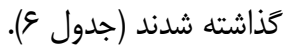

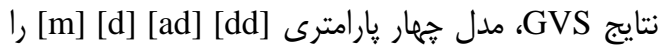
به عنوان بهترين مدل برازش يافته براى مدل عملكرد دانه دانه در سال

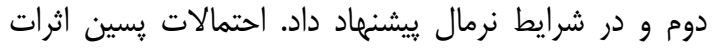

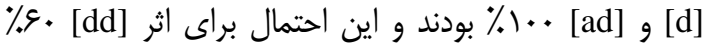

تلاقى هامون × دريا (C1)

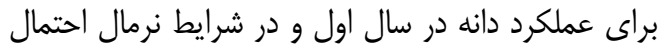

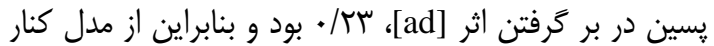

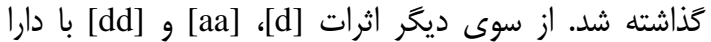

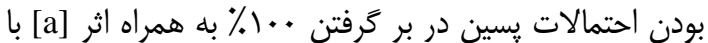

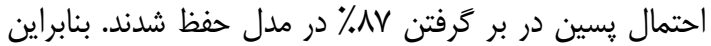

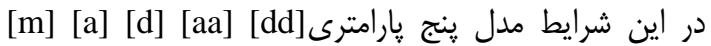

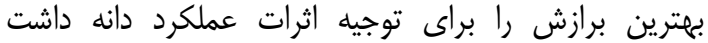

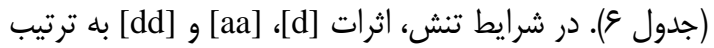

Table 2. Combined analysis of variance for grain yield (g/plant) for both crosses

جدول r- تجزيه واريانس مركب عملكرد دانه (گرم/ بوته) براى دو تلاقى (g)

\begin{tabular}{|c|c|c|c|}
\hline \multicolumn{2}{|c|}{ ميانكين مربعات } & \multirow{2}{*}{ درجه آزادى } & \multirow{2}{*}{ منبع تغييرات } \\
\hline سياهان × مرواريد & هامون × دريا & & \\
\hline 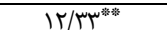 & $1 / \Delta \Lambda^{* * a s}$ & 1 & سال \\
\hline 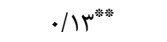 & $\cdot / \Delta 9^{* * 1 / 4}$ & r & تكرار (سال) \\
\hline $1 / \Upsilon^{* * * * *}$ & $1 / v \cdot e^{* * * * *}$ & 1 & تيمار \\
\hline$\cdot / \cdot \mathrm{r}^{\mathrm{ns}}$ &.$/ \mathrm{f}^{\mathrm{ns}}$ & 1 & سال × تيمار \\
\hline $.1 .9^{*}$ & $\cdot / Y^{* * * i n}$ & c & تيمار × تكرار (سال) \\
\hline $1 / \varphi^{* w^{*}}$ & 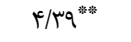 & $\wedge$ & 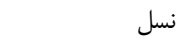 \\
\hline$\cdot / \cdot \gamma^{\text {部 }}$ & $\cdot / \Lambda^{\text {*tis }}$ & $\wedge$ & تيمار × نسل \\
\hline$\cdot / v^{* * *}$ & $\cdot / r)^{* * * n}$ & $\Delta$ & سال × نسل \\
\hline$\cdot 1 \cdot \mathrm{rs}^{\mathrm{ns}}$ & $.1 .8^{\mathrm{ns}}$ & $\Delta$ & سال × تيمار × نسل \\
\hline $9 / 9 \wedge$ & $11 / N r$ & & ضريب تغي \\
\hline
\end{tabular}

جدول س- تجزيه واريانس عملكرد دانه (گرم /بوته) براى سالهاى مختلف

Table 3. Analysis of variance for grain yield (g/plant) in different years

\begin{tabular}{|c|c|c|c|c|c|c|}
\hline \multicolumn{3}{|c|}{$1 \% 90$} & \multicolumn{3}{|c|}{1794} & \multirow{3}{*}{ منبع تغييرات } \\
\hline \multicolumn{2}{|c|}{ ميانگين مربعات } & \multirow{2}{*}{ درجه آزادى } & \multicolumn{2}{|c|}{ ميانگين مربعات } & \multirow{2}{*}{ درجه آزادى } & \\
\hline $\mathrm{C} 2$ & $\mathrm{C} 1$ & & $\mathrm{C} 2$ & $\mathrm{C} 1$ & & \\
\hline$\cdot / .^{\mathrm{nS}}$ & $\cdot / \cdot r^{\mathrm{ns}}$ & $r$ & $\cdot / T v^{\mathrm{ns}}$ & $\mathrm{T} / \mathrm{/V^{ \textrm {ns } }}$ & $r$ & تكرار \\
\hline$\cdot / F T^{\prime \prime}$ & $1 / M^{n s}$ & 1 & $1 / \cdot \lambda^{\mathrm{ns}}$ & $\cdot / r^{\mathrm{ns}}$ & 1 & تيمار \\
\hline$\cdot / \cdot v$ & . & r &.$/ 11$ &.$/ 19$ & r & خطاى كرت اصلى \\
\hline$\cdot / \pi r^{* * n}$ & $r / \Delta V^{* * a}$ & $\wedge$ & $r / 9)^{* * *}$ & $1 / 4 \Delta^{* * *}$ & $\Delta$ & نسل \\
\hline$\cdot / \cdot r^{* * m}$ & $\cdot / \cdot v^{* * *}$ & $\wedge$ & $\cdot / M \Lambda^{* *}$ & $\cdot 1 \Delta 0^{* * *}$ & $\Delta$ & نسل × تيمار \\
\hline $.1 \cdot 1$ &.$/ .4$ & r & .1 .4 & س & r. & خطاى كرت فرعى \\
\hline $\mathrm{V} / \mathrm{M}$ & $8 / 0$ & & $1 \cdot / \mu$ & $19 /{ }^{\prime} \mid$ & & ضريب تغييرات (\%) \\
\hline
\end{tabular}

جدول عا- برشدهى و مقايسه ميانخين اثرات متقابل عملكرد دانه (كرم/بوته) در شرايط آبيارى مطلوب (T) Table 4. Slicing and mean comparisons of interactions for grain yield (g/plant) under normal condition ( $\left.\mathrm{T}_{1}\right)$

\begin{tabular}{|c|c|c|c|c|c|c|c|c|}
\hline \multicolumn{2}{|c|}{ تلاقى دوم (سال دوم) } & \multicolumn{2}{|c|}{ تلاقى دوم (سال اول) } & \multicolumn{2}{|c|}{ تلاقى اول (سال دوم) } & \multicolumn{2}{|c|}{ تلاقى اول (سال اول) } & \multirow{2}{*}{$\begin{aligned} \text { اثر متقابل } \\
T_{1} \times P_{1}\end{aligned}$} \\
\hline $1 / \pi \%$. & $\mathrm{cd}$ & $1 / 4 \cdot r$ & d & 1//4. & $\mathrm{f}$ & $1 /$ TqV & $\mathrm{d}$ & \\
\hline $1 / 9 \vee 9$ & $\mathrm{a}$ & $r / N 1$. & $\mathrm{b}$ & $r / \kappa q$. & a & $r / r \Delta$ & $\mathrm{a}$ & $\mathrm{T}_{1} \times \mathrm{P}_{2}$ \\
\hline $1 / 4$ & b & $r / 4 \cdot 9$ & b & T/FTT & $\mathrm{c}$ & $r / \cdot \Lambda V$ & $\mathrm{bc}$ & $\mathrm{T}_{1} \times \mathrm{F}_{2}$ \\
\hline $1 / \cdot 1$. & d & $1 / 91 \%$ & c & $r / / r$. & d & $1 / 8 \cdot r$ & $\mathrm{~cd}$ & $\mathrm{~T}_{1} \times \mathrm{F}_{3}$ \\
\hline 1/ras & $\mathrm{bc}$ & - & & r/AVG & $\mathrm{b}$ & - & & $\mathrm{T}_{1} \times \mathrm{F}_{4}$ \\
\hline 1/194 & $\mathrm{cd}$ & $1 / 9 \vee r$ & $\mathrm{c}$ & $1 / 9 \Lambda$. & ef & $1 / \Delta / Q$ & $\mathrm{~cd}$ & $\mathrm{~T}_{1} \times \mathrm{BC}_{1} \mathrm{~S}_{1}$ \\
\hline 1/א & $\mathrm{d}$ & - & & $1 / 9 . r$ & de & - & & $\mathrm{T}_{1} \times \mathrm{BC}_{1} \mathrm{~S}_{2}$ \\
\hline 1/GTr & a & $\Gamma / N \Delta S$ & a & $r / F V G$ & $\mathrm{a}$ & $r /$ TNE & $\mathrm{b}$ & $\mathrm{T}_{1} \times \mathrm{BC}_{2} \mathrm{~S}_{1}$ \\
\hline 1/9r & $\mathrm{a}$ & - & & $r / q .$. & $\mathrm{a}$ & - & & $\mathrm{T}_{1} \times \mathrm{BC}_{2} \mathrm{~S}_{2}$ \\
\hline
\end{tabular}


جدول ه- برشدهى و مقايسه ميانخين اثرات متقابل عملكرد دانه (كرم /بوته) در شرايط تنش (T2) (T) Table 5. Slicing and mean comparisons of interactions for grain yield (g/plant) under stress condition ( $\left.\mathrm{T}_{2}\right)$

\begin{tabular}{|c|c|c|c|c|c|c|c|c|}
\hline \multicolumn{2}{|c|}{ تلاقى دوم (سال دوم) } & \multicolumn{2}{|c|}{ تلاقى دوم (سال اول) } & \multicolumn{2}{|c|}{ تلاقى اول (سال دوم) } & \multicolumn{2}{|c|}{ تلاقى اول (سال اول) } & \multirow{2}{*}{$\begin{array}{l}\text { اثر متقابل } \\
T_{2} \times P_{1}\end{array}$} \\
\hline.$/ 9 \vee$. & $\mathrm{e}$ & ./var & $\mathrm{d}$ & $1 / \Gamma \mid q$ & $\mathrm{~d}$ & I/TAT & $\mathrm{c}$ & \\
\hline $1 / / 4$. & $\mathrm{cd}$ & r/Mr. & $\mathrm{b}$ & r/avg & $\mathrm{a}$ & שזוא & $\mathrm{a}$ & $\mathrm{T}_{2} \times \mathrm{P}_{2}$ \\
\hline 1/r & $a b$ & $r / A^{V} V$. & $a b$ & $r / \uparrow \wedge$. & $\mathrm{b}$ & $T / T \cdot \Delta$ & $\mathrm{a}$ & $\mathrm{T}_{2} \times \mathrm{F}_{2}$ \\
\hline.$/ 998$ & de & I/GKG & $\mathrm{c}$ & $1 / N e$ & $\mathrm{c}$ & $1 / 9 \Delta V$ & $a b c$ & $\mathrm{~T}_{2} \times \mathrm{F}_{3}$ \\
\hline $1 / r \cdot r$ & $\mathrm{bc}$ & - & & $r / \cdot \Lambda \mu$ & $\mathrm{c}$ & - & & $\mathrm{T}_{2} \times \mathrm{F}_{4}$ \\
\hline $1 / .1 \%$ & de & $1 / 998$ & $\mathrm{c}$ & $1 / \% 1$. & d & $1 / 419$ & $\mathrm{bc}$ & $\mathrm{T}_{2} \times \mathrm{BC}_{1} \mathrm{~S}_{1}$ \\
\hline $1 / \cdot \wedge \mu$ & cde & - & & $1 / \Delta \Delta$. & $\mathrm{d}$ & - & & $\mathrm{T}_{2} \times \mathrm{BC}_{1} \mathrm{~S}_{2}$ \\
\hline $1 / 49$ & a & r/Vag & $\mathrm{a}$ & $r / .9$. & a & $r / . . \varphi$ & $\mathrm{ab}$ & $\mathrm{T}_{2} \times \mathrm{BC}_{2} \mathrm{~S}_{1}$ \\
\hline $1 / \uparrow \wedge$ & $\mathrm{a}$ & - & & $r / Y)$. & $\mathrm{a}$ & - & & $\mathrm{T}_{2} \times \mathrm{BC}_{2} \mathrm{~S}_{2}$ \\
\hline
\end{tabular}

Table 6. Posterior inclusion probabilities of effects for grain yield model

جدول צ- احتمالات پِين در بر گرفتن اثرات براى مدل عملكرد دانه

\begin{tabular}{|c|c|c|c|c|c|}
\hline \multicolumn{5}{|c|}{ اثرات } & \multirow{2}{*}{ عملكرد دانه (كرم/بوته) } \\
\hline [dd] & [ad] & [aa] & [d] & [a] & \\
\hline $1 / \cdot \cdot$ & . & $1 / \cdot \cdot$ & $1 / \cdot \cdot$ & ./AV & تلاقى هامون × دريا (سال اول؛ آبيارى) \\
\hline.$/ 94$ &.$/ 4 q$ &.$/ 99$ & $1 / \cdot \cdot$ &.$/ \% \omega$ & تلاقى هامون × دريا (سال اول؛ تنش) \\
\hline.$/ 9$ & $1 / \cdot$ & $.1 \cdot 1$ & $1 / \cdot$ &. & تلاقى هامون × دريا (سال دوم؛ آبيارى) \\
\hline .11 &.$/ 94$ & $\cdot / \Lambda \Delta$ & .1 .9 & $1 / \cdot$ & تلاقى هامون × دريا (سال دوم؛ تنش) \\
\hline $1 /$. & . & $1 /$. & $1 / \cdot \cdot$ & $1 /$. & تلاقى سياهان × مرواريد (سال اول؛ آبيارى) \\
\hline $1 /$. &.$/ 94$ & $1 /$. & $1 / \cdot \cdot$ & $1 / .$. & تلاقى سياهان × مرواريد (سال اول؛ تنش) \\
\hline.$/ 14$ &.$/ 14$ & $1 / \cdot$ &.$/ \cdot r$ & $1 / \cdot$ & تلاقى سياهان × مرواريد (سال دوم؛ آبيارى) \\
\hline . & $1 / \cdot$ & $.1 \cdot 1$ &.$/ \cdot 1$ & .1 .9 & تلاقى سياهان × مرواريد (سال دوم؛ تنش) \\
\hline
\end{tabular}

براى يارامترهاى مورد نظر هستند براى مهرمترين اثرات

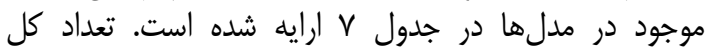

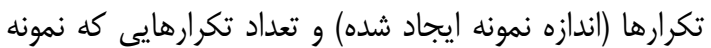

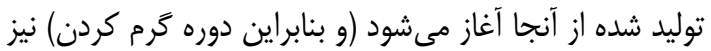

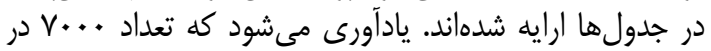

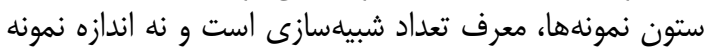

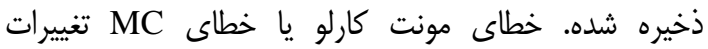

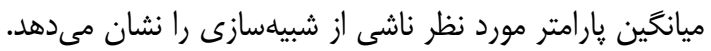

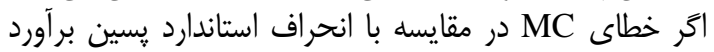

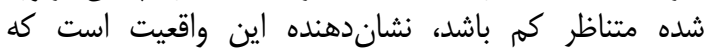

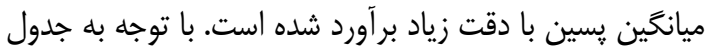

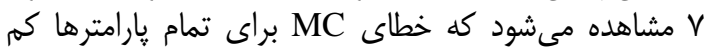

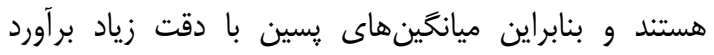

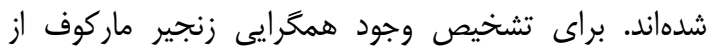

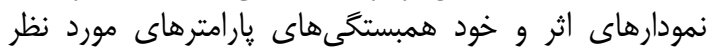

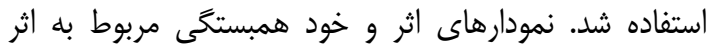

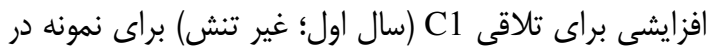

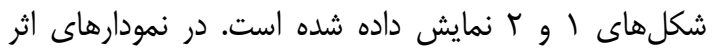

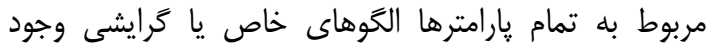

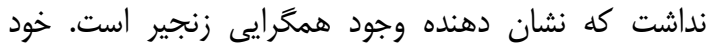

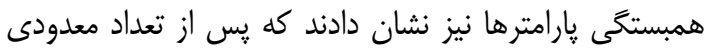

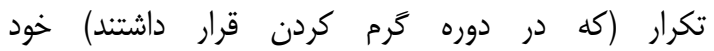

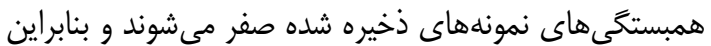

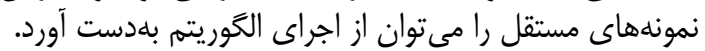

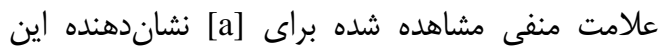

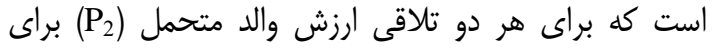

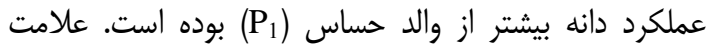

اثر افزايشى و اثر متقابل افزايشى × افزايشى احتمالات

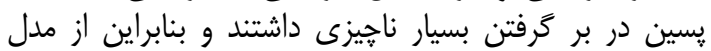

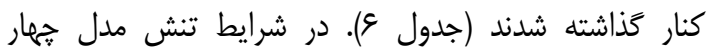
يارامترى [m] [a] [aa] [ad] بهترين مدل بود. در شرايط

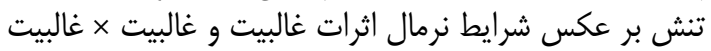

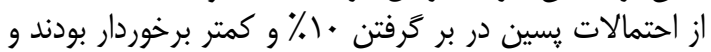

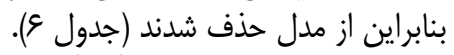

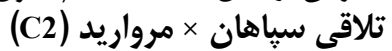

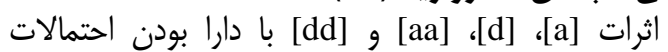

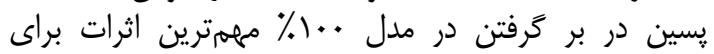

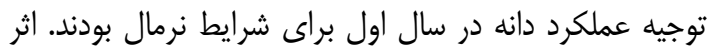

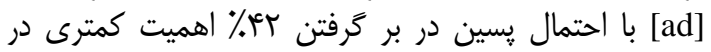

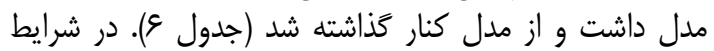

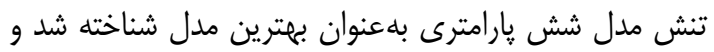

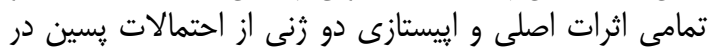

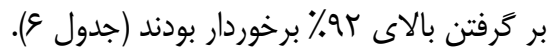

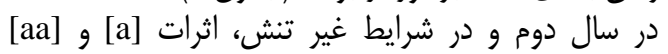

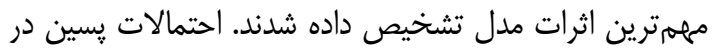

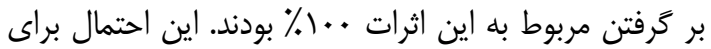

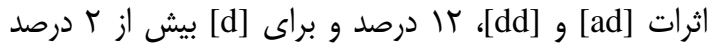

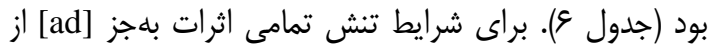

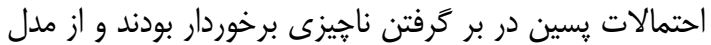

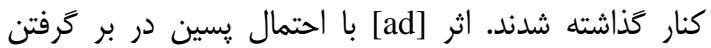

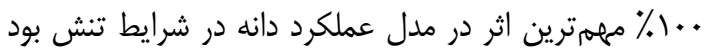

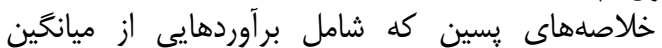

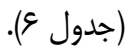

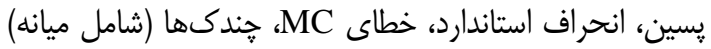




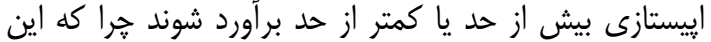

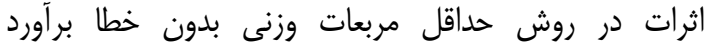

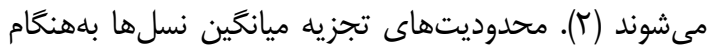

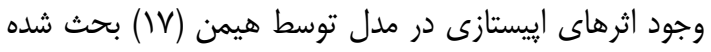

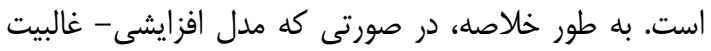

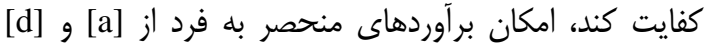

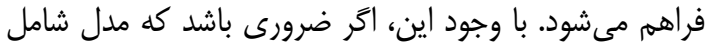

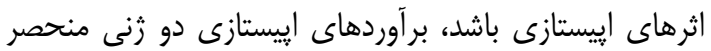

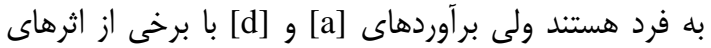

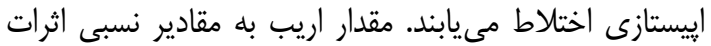

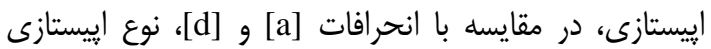

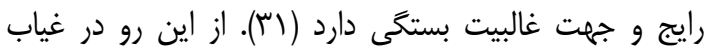

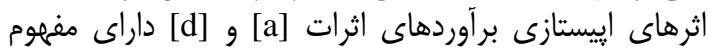

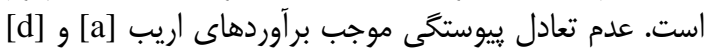

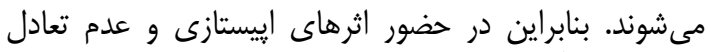

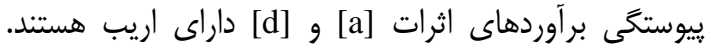

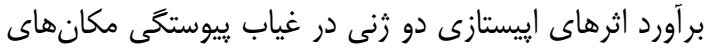

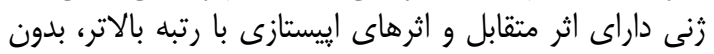

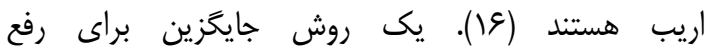
محدوديتهاى آزمون مقياس مشترك استفاده از استباط بيزى و كزينش مدل است.
متضاد براى [a] و [aa] مىتواند حاكى از ماهيت متفاوت اين

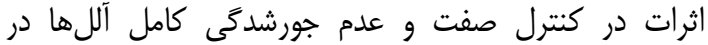

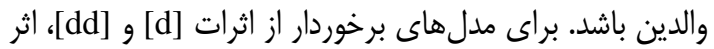

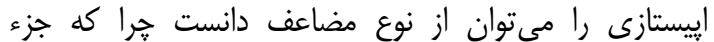
غالبيت [d] و اثر متقابل غالبيت × غالبيت [dd] معنى ماردار و داراى علامتهاى مخالف مالف بودند. علامت ماليت مناليت منفى اثر متقابل

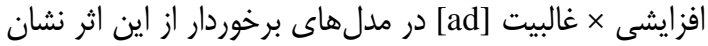
دهنده يراكندگى ثنى داليت در والدين است.

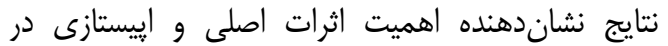

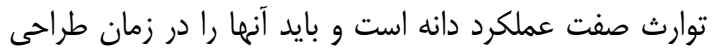

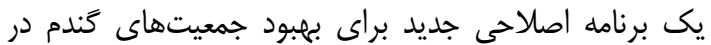

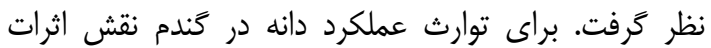

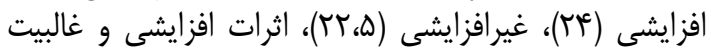

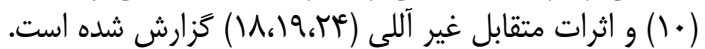

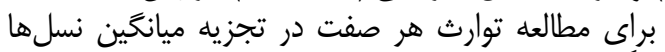

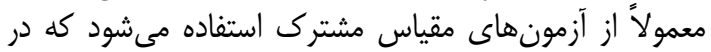

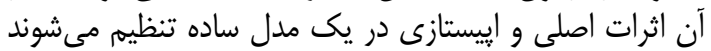

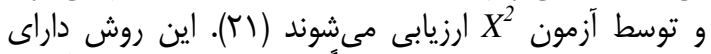

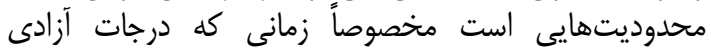

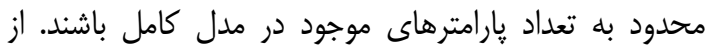

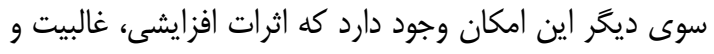

جدول V- خلاصههاى پسين مهرترين اثرات مدل براى عملكرد دانه (كرم/بوته) Table 7. Posterior summaries of the most important model effects for grain yield (g/plant)

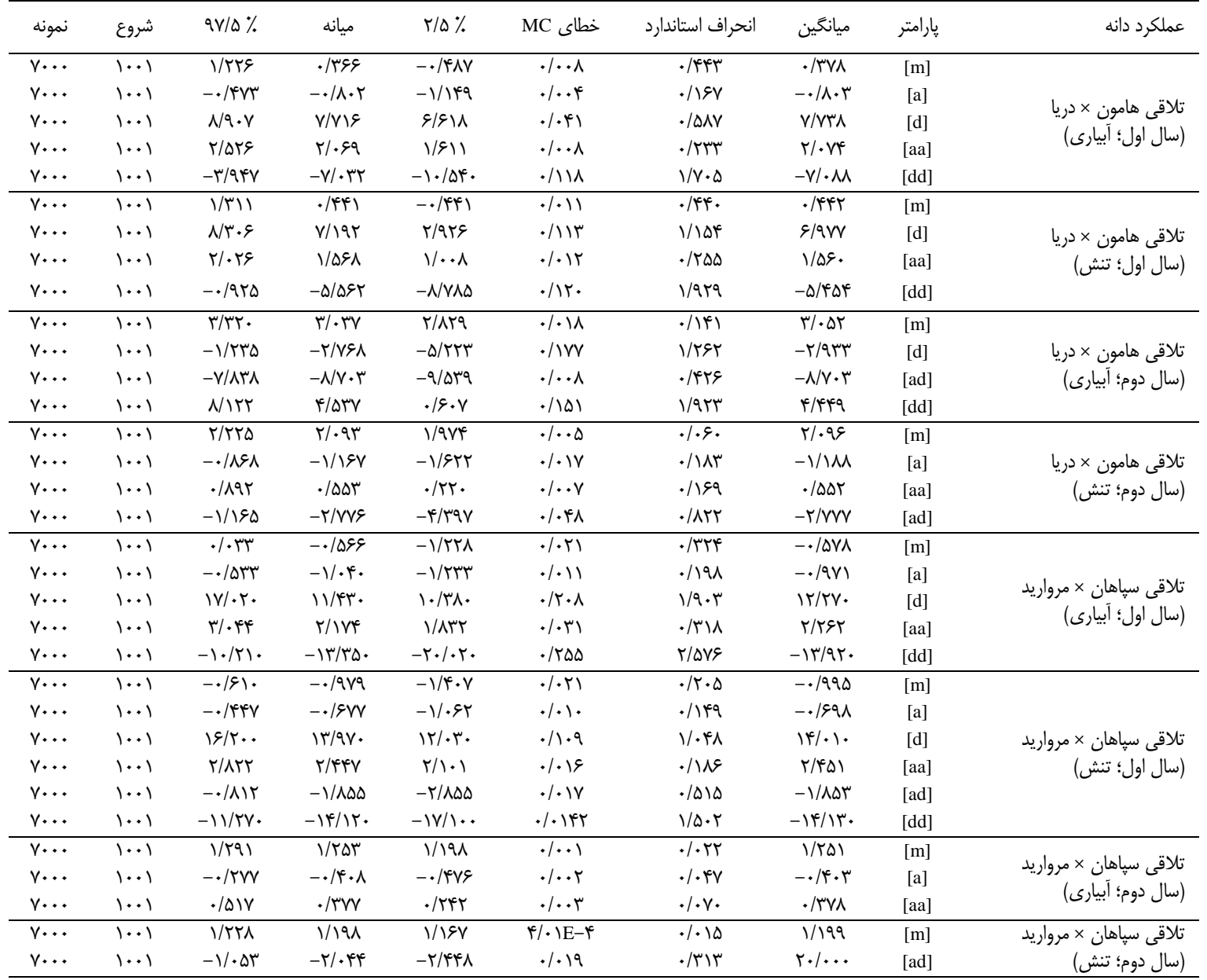




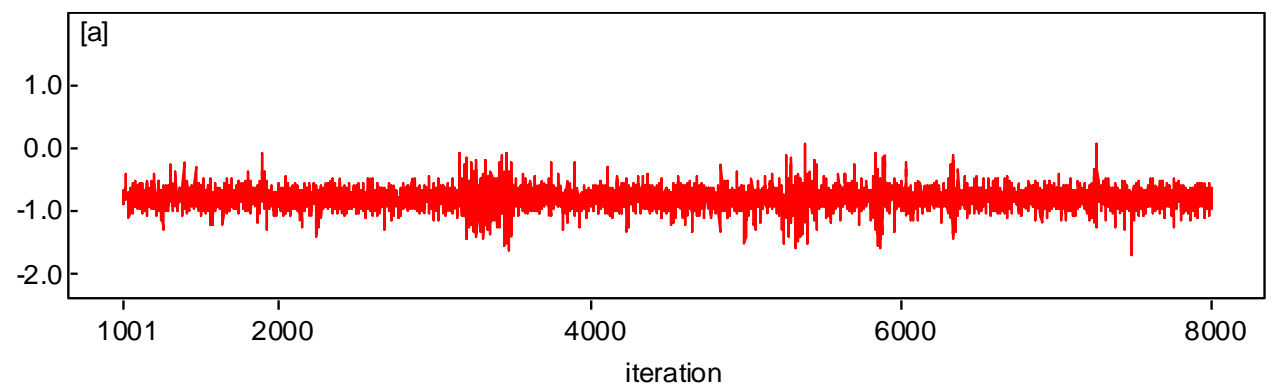

شكل ا - نمودار اثر مربوط به اثر افزايشى براى تلاقى C1 (سال اول؛ آبيارى) براى آزمون همخرايى زنجيره عملكرد دانه Figure 1. Trace plot for additive effect of C1 (2015; normal) to assess chain convergence of grain yield

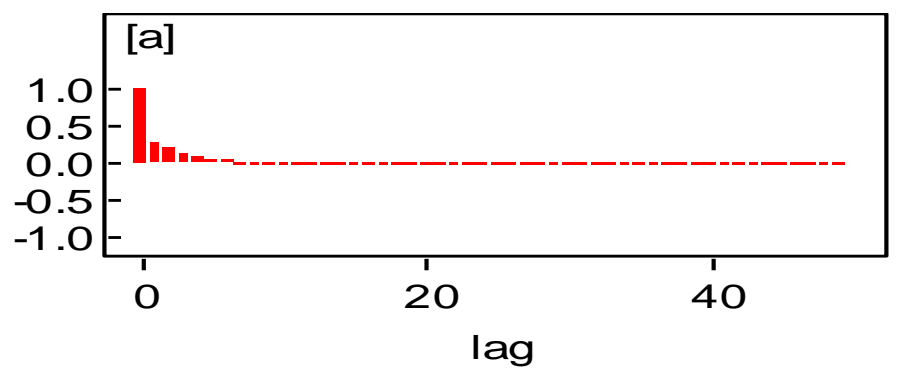

شكل r- نمودار خود همبستخى اثر افزايشى براى تلاقى C1 (سال اول؛ آبيارى) براى عملكرد دانه

Figure 2. Autocorrelation plot related to additive effect of C1 (2015; normal) for grain yield

اثرات مهم موجود در مدل را بهبود مىبخشد. بر اساس نتايج

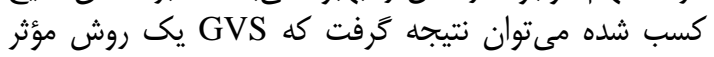

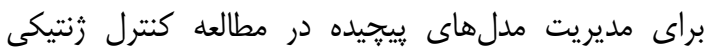

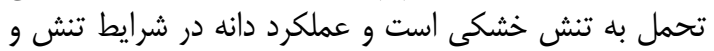

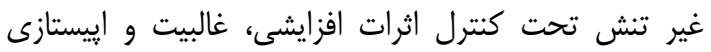

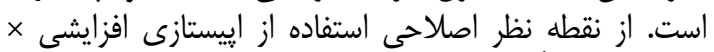

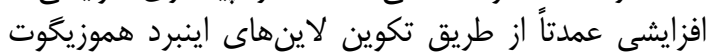

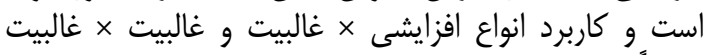

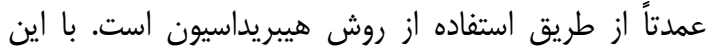

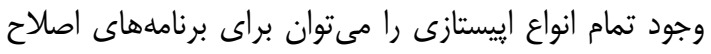

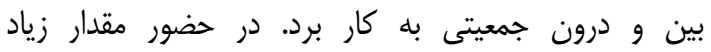

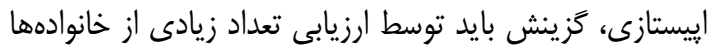

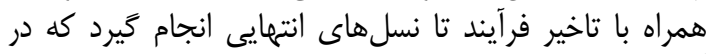

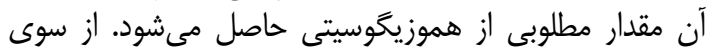

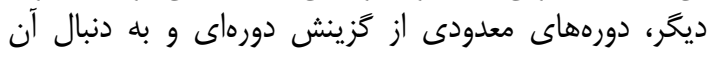

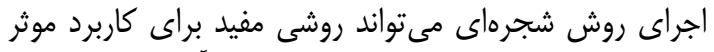

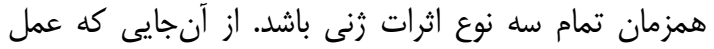

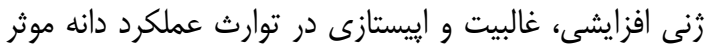

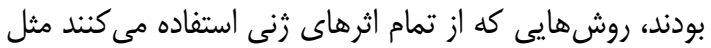

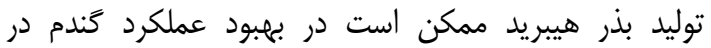
شرايط مختلف موثر باشد.

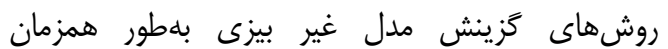

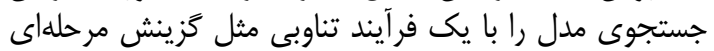

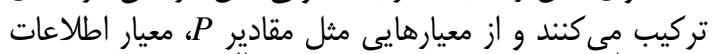

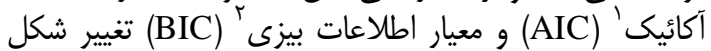

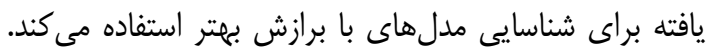

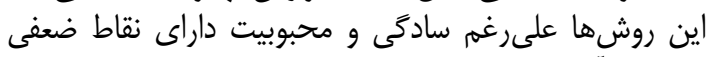

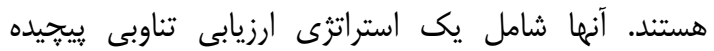

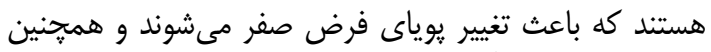

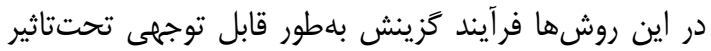

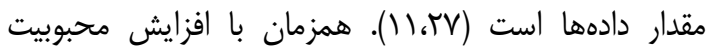
روشهاى بيزى جند روش جديد ابداع شدند كه امكان انتخاب

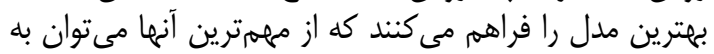

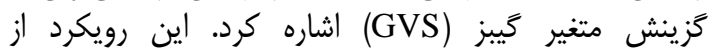

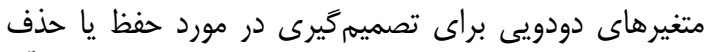

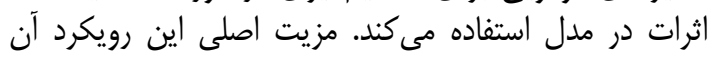

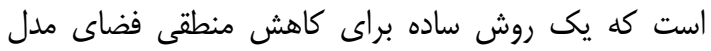

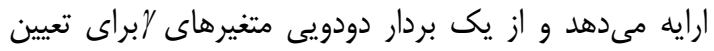

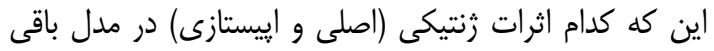

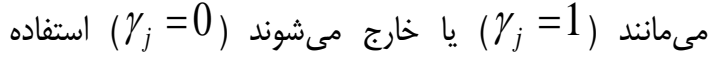

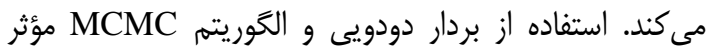
بهطور قابل توجهى توانايى GVS را براى شناسايى سريع 

Ahmadian, S., S.M. Mortazavian, M. Ebrahimi, F. Amini, M. Ghorbani Javid and B. Foghi. 2017. Genetic Analysis of some Morphological Traits in Wheat using Generation Mean Analysis under Normal and Drought Stress Conditions. Journal of Crop Breeding, 8(20): 182-175 (In Persian).

2. Balestre, M., R.G. Von Pinho and A.H. Brito. 2012. Bayesian inference to study genetic control of resistance to gray leaf spot in maize. Genetics and Molecular Research, 11(1): 17-29.

3. Barbieri, M.M. and J.O. Berger. 2004. Optimal predictive model selection. Annals of Statistics, 870-897.

4. Carlin, B.P. and S. Chib. 1995. Bayesian model choice via Markov chain Monte Carlo methods. Journal of the Royal Statistical Society, 473-484.

5. Chowdhry, M.A., M. Rafiq and K. Alam. 1992. Genetic architecture of grain yield and certain other traits in bread wheat. Pakistan Journal of Agricultural Research, 13(3): 216-220.

6. Clyde, M., H. Desimone and G. Parmigiani. 1996. Prediction via orthogonalized model mixing. Journal of the American Statistical Association, 91(435): 1197-1208.

7. Dellaportas, P., J.J. Forster and I. Ntzoufras. 2000. Bayesian Variable Selection Using the Gibbs Sampler, In: Dey, D.K., S.K. Ghosh and B.K. Mallick (eds.) Generalized Linear Models: A Bayesian Perspective, CRC Press, New York, 271-286.

8. Dellaportas, P., J.J. Forster and I. Ntzoufras. 2002. On Bayesian model and variable selection using MCMC. Statistics and Computing, 12(1): 27-36.

9. Eftekhari, A., A. Baghizadeh, R. Abdoshahi and M.M. Yaghoubi. 2017. Estimation of Genes Effect and Combining Ability of Agronomic Traits in Some Bread Wheat Varieties under Drought Stress. Journal of Crop Breeding, 9(22): 98-108 (In Persian).

10. Fotokian, M.H., J. Ahmadi, and S.F. Orang. 2008. Genetic assay of some traits in wheat (Triticum aestivum L.) under drought stress condition using generation mean analysis. Iranian Journal of Biology, 22(3): 431441 (In Persian).

11. Gelman, A., J.B. Carlin, H.S. Stern and D.B. Rubin. 2004. Bayesian data analysis. Boca Raton, FL, USA: Chapman \& Hall/CRC.

12. Geman, S. and D. Geman. 1984. Stochastic relaxation, Gibbs distributions, and the Bayesian restoration of images. IEEE Transactions on Pattern Analysis and Machine Intelligence, 6: 721-741.

13. George, E.I. and R.E. McCulloch. 1993. Variable selection via Gibbs sampling. Journal of the American Statistical Association, 88(423): 881-889.

14. Gomez, K.A. and A.A. Gomez. 1984. Statistical Procedures for Agricultural Research. John Wiley \& Sons.

15. Green, P.J. 1995. Reversible jump Markov chain Monte Carlo computation and Bayesian model determination. Biometrika, 711-732.

16. Hallauer, A.R., M.J. Carena and J.B. Miranda Filho. 2010. Quantitative Genetics in Maize Breeding. Springer, New York.

17. Hayman, B.I. 1960. The separation of epistatic from additive and dominance variation in generation means. Heredity, 12: 371-390.

18. Ijaz, U.S. and M. Kashif. 2013. Genetic study of quantitative traits in spring wheat through generation means analysis. American-Eurasian Journal of Agricultural \& Environmental Sciences, 13(2): 191-197.

19. Khattab, S.A.M., R.M. Esmail and A.M.F. Al-Ansary. 2010. Genetical analysis of some quantitative traits in bread wheat (Triticum aestivum L.). New York Science Journal, 3(11): 152-157.

20. Kuo, L. and B. Mallick. 1998. Variable selection for regression models. Sankhyā: The Indian Journal of Statistics, Series B: 65-81.

21. Mather, K. and J.L. Jinks. 1971. Biometrical Genetics. Cornell University Press, Ithaca, N.Y.

22. Munir, M., M.A. Chowdhry and M. Ahsan. 2007. Generation means studies in bread wheat under drought condition. International Journal of Agriculture and Biology, (9)2: 282-286.

23. Nezhadahmadi, A., Z.H. Prodhan and G. Faruq. 2013. Drought tolerance in wheat. The Scientific World Journal, $12 \mathrm{pp}$.

24. Novoselovic, D., M. Baric, G. Drezner, J. Gunjaca and A. Lalic. 2004. Quantitative inheritance of some wheat plant traits. Genetics and Molecular Biology, 27(1): 92-98.

25. Ntzoufras, I. 2002. Gibbs variable selection using BUGS. Journal of statistical software, 7(7): 1-19.

26. Ntzoufras, I. 2011. Bayesian modeling using WinBUGS. John Wiley \& Sons, 698pp.

27. Raftery, A.E., D. Madigan and J.A. Hoeting. 1997. Bayesian model averaging for linear regression models. Journal of the American Statistical Association, 92(437): 179-191.

28. SAS Institute. 2002. SAS user's guide: Statistics version 9 for windows. SAS Institute, Carry, NC.

29. Siani, H.S. and D. Aspinall. 1981. Effects of water deficit on sporogensis in wheat. Annals of Botany, 43: 623-633.

30. Spiegelhalter, D.J., A. Thomas, N.G. Best and D. Lunn. 2003. WinBUGS user manual. MRC Biostatistics Unit, Cambridge.

31. Viana, J. and M. Soriano. 2000. Generation mean analysis in relation to polygenic systems with epistasis and fixed genes. Pesquisa Agropecuária Brasileira, 35(6): 1159-1167.

32. Xu, S. 2003. Estimating polygenic effects using markers of the entire genome. Genetics, 163(2): 789-801.

33. Yi, N., B.S. Yandell, G.A. Churchill, D.B. Allison, E.J. Eisen and D. Pomp. 2005. Bayesian model selection for genome-wide epistatic quantitative trait loci analysis. Genetics, 170(3): 1333-1344.

34. Yi, N., D. Shriner, S. Baneriee, T. Mehta, D. Pomp and B.S. Yandell. 2007. An efficient Bayesian model selection approach for interacting quantitative trait loci models with many effects. Genetics, 176(3): 18651877. 


\title{
Application of Gibbs Variable Selection Approach to Study Genetic Control of Water Deficient Stress Tolerance in Wheat
}

\section{Parviz Safari ${ }^{1}$, Seyedeh Fatemeh Danyali ${ }^{1}$, Mehdi Rahimi ${ }^{2}$ and Ahmad Mahdavi Meyghan ${ }^{3}$}

1- Graduated Ph.D., Department of Plant Breeding and Biotechnology, Faculty of Agriculture, University of Tabriz, Tabriz, Iran

2- Department of Biotechnology, Institute of Science and High Technology and Environmental Sciences, Graduate University of Advanced Technology, Kerman, Iran, (Corresponding author: mehdi83ra@ yahoo.com)

3- PhD student of plant breeding, Department of Agronomy and Plant Breeding, Faculty of Agricultural Science, University of Guilan, Rasht, Iran

Received: Jun 12, $2017 \quad$ Accepted: April 3, 2018

\begin{abstract}
Drought is the main abiotic stress seriously influencing wheat production and quality in Iran. Information about genetic controlling drought tolerance inheritance for grain yield is necessary to determine the type of breeding program as well as develop tolerant cultivars, enabling breeders to choose the most appropriate strategy to breeding trait of interest. In this study, Bayesian inference using Gibbs variable selection (GVS) approach used to identify the most important gene effects related to drought tolerance in context generation mean analysis. For this purpose, field experiments consist of two pairs of crosses with non-tolerant and tolerant cultivars and generations derived from them were carried out across two years as split plot designs based on RCBD with three replications in which main plots assigned to irrigation treatment consist of two levels (well watered and cessation of irrigation at pollination stage) and sub-plots given to the generations. To study the inheritance of any trait in generation mean analysis, joint scaling test is applied. Restrictions of degrees of freedom to number of parameters of model and over- or underestimation of the main and epistatic effects are disadvantages of this method. An alternative approach to obviate these limitations is to perform Bayesian inference and model selection strategies like GVS. GVS using estimation of posterior inclusion probabilities of effects identifies the most discriminant effects in the model. Since the additive, dominance and epistatic gene actions involved in drought tolerance inheritance, methods which utilize all type of gene effects, like recurrent selection followed by pedigree method may be useful for drought tolerance stress improvement. Also hybrid seed production, which utilizes all types of gene effects, may be useful in improving yield in wheat.
\end{abstract}

Keywords: Bayesian inference, Generation mean analysis, Joint scaling test 